\title{
Contribuições do ensino da Educação Física para o trabalho com o conhecimento teórico na escola
}

\author{
Carolina Picchetti Nascimento ${ }^{1}$ \\ Elaine Sampaio Araujo ${ }^{2}$
}

\begin{abstract}
RESUMO
O objetivo deste estudo foi caracterizar o processo de organização do ensino que contribua para o desenvolvimento do pensamento teórico dos sujeitos da atividade pedagógica, professores e estudantes. Tendo a Atividade Orientadora de Ensino, proposta por Moura (1996, 2000, 2016), como fundamento teórico-metodológico apresentam-se interpretações didáticas sobre a tese vigotskiana de que "o único bom ensino é o que se adianta ao desenvolvimento". Do ponto de vista das ações metodológicas discute-se o significado pedagógico do trabalho com o conhecimento teórico na escola por meio da análise de momentos-chave de uma situação formativa realizada com professoras da educação básica, no contexto de um projeto de pesquisa voltado à melhoria do ensino público. Busca-se evidenciar, então, nos processos de organização do ensino, como os conhecimentos propostos na atividade pedagógica podem se realizar como conceitos teóricos para os sujeitos em suas ações de estudo.
\end{abstract}

PALAVRAS-CHAVE: Atividade Orientadora de Ensino. Teoria Histórico-Cultural. Pensamento Teórico. Ensino Desenvolvimental. Ensino de Educação Física.

Contributions of Physical Education teaching for working with theoretical knowledge in school

\section{ABSTRACT}

\footnotetext{
1 Doutora em Educação pela USP. Docente na Universidade Federal de Santa Catarina, Florianópolis, SC. https://orcid.org/0000-0002-8146-6771. carolina_picchetti@hotmail.com.

${ }^{2}$ Doutora em Educação pela USP. Docente na Universidade de São Paulo, Ribeirão Preto, SP. https://orcid.org/00000002-5012-5552.esaraujo@usp.br.
} 
The purpose of this study was to characterize the process of teaching organization that contributes to the development of theoretical thinking of the subjects of pedagogical activity, teachers and students. Having the Teaching Guiding Activity, proposed by Moura (1996, 2000, 2016), as a theoretical-methodological foundation it is proposed didactics interpretations about Vygotsky's thesis that "the only good learning is that which is in advance of development". Considering the methodological actions, it is discussed the pedagogical meaning of working with theoretical knowledge in schooling process through the analysis of key moments of a formative situation carried out with teachers of elementary education in the context of a research project focused on the improvement of public teaching. It seeks to show, then, int the processes of teaching organization how the knowledge proposed in the pedagogical activity can be realized as theoretical concepts to the subjects in their actions of study.

KEYWORDS: Teaching Guiding Activity. Cultural-Historical Theory. Theoretical Thought. Developmental Teaching. Physical Education teaching.

$$
* * *
$$

\section{Introdução ${ }^{3}$}

Apresentamos neste texto algumas interpretações didáticas sobre a tese vigotskiana de que "o único bom ensino é o que se adianta ao desenvolvimento" (VIGOTSKII, 1988, p. 114) elegendo, como foco, discutir o significado pedagógico do trabalho com os conhecimentos teóricos (DAVIDOV, 1988) ou científicos (VIGOTSKI, 2009) na escola.

Assumindo o pressuposto geral de que o trabalho escolar, de todos os componentes curriculares, deve estar orientado para que “[...] de forma concisa, abreviada, reproduza o processo histórico real de gênese e desenvolvimento dos conhecimentos" (DAVIDOV, 1988, p.174), temos como objetivo neste artigo caracterizar o processo de organização do ensino que

\footnotetext{
${ }^{3}$ Parte desse texto foi publicado nos anais do IV Colóquio sobre Ensino Desenvolvimental (2018), tendo sido ampliado e modificado para a sua publicação na presente revista.
} 
contribua para o desenvolvimento do pensamento teórico dos sujeitos da atividade pedagógica, professores e estudantes.

Metodologicamente, analisamos alguns momentos-chave de uma situação formadora realizada com professoras da educação básica, no contexto de um projeto de pesquisa financiado pela Fundação de Amparo à Pesquisa do Estado de São Paulo (FAPESP), no âmbito do Programa Melhoria do Ensino Público. Tal projeto, voltado à organização curricular, abordou neste estudo o componente Educação Física como referência para o trabalho formativo. A análise desta situação nos permitiu evidenciar os elementos pedagógicos e didáticos a partir dos quais os conhecimentos teóricos propostos na atividade pedagógica, aparecem e se realizam para os sujeitos em suas ações de estudo.

A partir do referencial teórico assumido podemos compreender que o conhecimento representa uma síntese lógica do processo histórico de busca de solução para uma determinada necessidade surgida na prática social. $\mathrm{O}$ "conhecimento", que expressa o mundo na sua condição de objeto da atividade humana (MARX, 2004; KOPNIN, 1978; VYGOTSKI, 1995; LEONTIEV, 1983; 1978), consitui-se, assim, como conhecimento objetivo.

Por essa razão, uma das tarefas centrais da atividade docente, ao se propor trabalhar com o conhecimento teórico na escola, está em organizar ações de ensino e de estudo que permitam aos sujeitos atuarem com o problema fundamental que levou a humanidade à produção de um determinado conhecimento (DAVIDOV, 1988; CHAIKLIN, 1999; ILYENKOV, 2007b; MOURA et al 2016). Esse modo de organização do ensino pode, então, contribuir para o desenvolvimento do pensamento teórico dos sujeitos da atividade pedagógica, professores e estudantes, nas diferentes áreas de conhecimento.

Questões metodológicas: a situação desencadeadora de aprendizagem como instrumento para a organização e a análise do ensino 
A presente discussão sobre o significado pedagógico do trabalho com o conhecimento teórico na escola fundamenta-se nos princípios teóricometodológicos da Atividade Orientadora de Ensino (MOURA, 1996; 2000; MOURA et al. 2016), instrumento que possibilita à professores e pesquisadores sistematizarem para si os elementos centrais para a organização de um ensino promotor do desenvolvimento dos sujeitos.

Para essa perspectiva, desenvolvimento refere-se ao processo especificamente humano de autodomínio da conduta (VYGOTSKI, 1995) através da apropriação do processo de elaboração e utilização de signos (VYGOTSKI, 1995), isto é, meios especialmente destinados à resolver alguma tarefa psicológica (escolher, memorizar, informar, comparar etc.). Como resultado, esse processo permite a formação das chamadas "funções psicológicas superiores" (VYGOTSKI, 1995).

Do ponto de vista das ações metodológicas descrevemos, neste artigo, momentos-chave de uma situação formativa realizada com professoras da educação básica ${ }^{4}$, na qual se trabalhou com o conteúdo "dança", no âmbito da Educação Física. Embora essa situação tenha se realizado na relação formador - professor, procuramos evidenciar ao longo do artigo em que medida o modo de estruturar o ensino presente em tal situação é igualmente pertinente para a organização do ensino na educação básica, na relação professor - estudante.

Ao longo desta análise destacamos os três momentos gerais que compõem a atividade pedagógica a partir dos princípios teóricometodológicos da Atividade Orientadora de Ensino: i) a sistematização do movimento lógico-histórico do conceito; ii) a formulação de um problema desencadeador de aprendizagem; iii) a proposição de uma situação desencadeadora de aprendizagem.

\footnotetext{
${ }^{4}$ Situação realizada com sete professoras de uma rede municipal do Estado de São Paulo, compondo parte da pesquisa de pós-doutorado desenvolvida pelas autoras. O trabalho com as professoras ocorreu durante o segundo semestre de 2016, totalizando cinco encontros, de cerca de três horas cada. Todo os encontros foram gravados em vídeo e registrados em caderno de campo, tendo a anuência das professoras para tal.
} 
O processo de sistematização do movimento lógico-histórico do conceito permite ao professor compreender um determinado conteúdo de ensino como expressão do processo histórico que levou a humanidade à produzir tal conhecimento. Compreende-se que um conhecimento sintetiza logicamente a relação histórica entre um problema real enfrentado pela humanidade e os modos específicos que foram permitindo a sua solução, processo denominado por Kopnin (1978) de "movimento lógico-histórico do conceito".

O conceito, assim, constitui-se como tal na medida em que passa a expressar um determinado "sistema" (VIGOTSKI, 2009), evidenciando as relações ou os "nexos conceituais" (DAVIDOV, 1988) com os quais os sujeitos precisam necessariamente agir para reconstituirem para si tal conceito. (DAVIDOV, 1988; CHAIKLIN, 1999).

Esses nexos conceituais configuram-se como ponto de partida efetivo da atividade de ensino do professor, mas aparecem, na atividade de aprendizagem dos estudantes, como o ponto de chegada de suas ações de estudo, como o resultado de sua atividade direcionada a resolver um determinado problema proposto pela atividade pedagógica. Neste sentido, este problema deve ser capaz de sintetizar a necessidade histórica que levou a humanidade à produção do conhecimento que se quer ensinar. Esse é o papel didático da formulação de um problema desencadeador de aprendizagem na Atividade Orientadora de Ensino. Busca-se, com ele, desencadear a necessidade pessoal de recriar para si a atividade humana encarnada no conceito, gerando um processo no qual o significado social do conhecimento possa coincidir com o conhecimento pessoalmente significativo para o sujeito (RUBINSTEIN, 1973).

Nas ações de ensino e de aprendizagem o problema desencadeador aparece sob determinadas condições singulares, isto é, materializado sob a forma de uma situação desencadeadora de aprendizagem. Esta, busca criar os meios ou instrumentos para que os sujeitos se engagem no processo de resolução daquele problema que sintetiza o conceito que se quer ensinar. 
Esses três momentos da organização do ensino (a sistematização do movimento lógico-histórico do conceito, a formulação de um problema desencadeador de aprendizagem e a proposição de uma situação desencadeadora de aprendizagem) sintetizam modos de ação que vêm configurando a Atividade Orientadora de Ensino como um princípio teóricometodológico para a organização e, também, para a análise de um ensino promotor do desenvolvimento do pensamento teórico dos sujeitos. (ARAÚJO; MORAES, 2017). A partir desses princípios que a situação formativa discutida neste artigo foi elaborada e, posteriormente, analisada.

\section{Uma situação desencadeadora de aprendizagem para o trabalho com o conhecimento teórico}

Analisamos nesta seção uma situação desencadeadora de aprendizagem proposta em um trabalho de formação contínua com professoras da educação básica e que abordou um conteúdo de ensino específico presente no componente curricular de Educação Física: a Dança.

A perspectiva deste trabalho era gerar nas professoras a necessidade de uma reflexão pedagógica sobre "o que é a dança como atividade humana" e sobre o que ela pode vir a ser para a formação dos sujeitos: qual o sentido de um estudo sobre a Dança na escola? Em que medida podemos falar em um "conhecimento teórico" no campo da Dança como conteúdo da área de Educação Física? Para promover essas reflexões entre as professoras foi proposta uma situação desencadeadora de aprendizagem que buscava sintetizar a necessidade social que gerou o processo de desenvolvimento da dança como atividade humana (NASCIMENTO, 2014; BOURCIER, 2001; CAMINADA, 1999).

A elaboração dessa situação (figura 1) foi inspirada em um dos elementos históricos que explicam o processo de desenvolvimento da dança como atividade artística nas sociedades ocidentais: a crescente especialização das danças, tanto dos sujeitos que poderiam dançar quanto 
dos próprios gestos corporais (BOURCIER, 2001; CAMINADA, 1999), no contexto de sua prática como ato ritualístico. Ocorre que a "[...] classe sacerdotal, cujo papel é manter contato com as divindades protetoras, não deixará os atos rituais e as danças ao acaso das inspirações individuais" (BOURCIER, 2001, p. 10).

FIGURA 1: Uma situação desencadeadora de aprendizagem para o estudo da Dança

As sacerdotisas preparavam os rituais litúrgicos com a Dança de modo a agradar às
personalidades de Dionísio [festa], Hades [morte] e Ares [guerra]. Utilizavam para o ritual de
cada Deus uma mesma sequência de movimentos: "deslocar-se para frente; movimentar os
braços; saltar; agachar". Mas ainda assim cada dança era capaz de satisfazer certeiramente a
personalidade de cada um dos três Deuses.
Esse fato curioso intrigava o filósofo e seus pupilos: as sacerdotisas deveriam realizar
alguma ação importante que lhes permitia tamanha precisão na comunicação com os Deuses
a despeito de sempre usarem a mesma sequencia de movimentos. Descobrir essa ação das
sacerdotisas que lhes permitia uma comunicação efetiva com qualquer Deus, era a tarefa do
filósofo e seus pupilos. Ao final de um primeiro debate com a questão o filósofo declarou aos
pupilos:
- Peço que dancem. Façam como se fossem as sacerdotisas. Depois, escrevam suas
conclusões para nossa questão e venham comunicá-las na próxima lua cheia. Estarei aqui e
chegaremos a uma resposta.

Fonte: produção das autoras

No trabalho com as professoras participantes, após lermos juntas a situação desencadeadora, buscamos promover uma reflexão coletiva sobre qual era o problema que estava sendo proposto e para o qual deveríamos buscar respostas. O problema desencadeador de aprendizagem que aparece inicialmente nesta situação de ensino refere-se à descoberta do modo de ação das sacerdotisas que, expressando as relações essenciais da dança, lhes permitia criar diferentes danças para qualquer Deus.

Após alguns debates este problema tornou-se compreensível para as professoras, no sentido de poderem verbalizá-lo. Contudo, essa verbalização, em si, não foi capaz de transformar o problema em um elemento propriamente orientador e mobilizador das ações de estudo das professoras, o que pode ser evidenciado por meio das primeiras soluções propostas por 
elas: "precisa de sincronia dos deuses amparado pela música"; "uma ação conjunta, coletiva”; "cada um fazer movimentos diferentes" 5. Tais respostas, que são mais ou menos diretas ou imediatas, denotam uma compreensão também imediata, direta ou, ainda, empírica, do problema proposto na situação desencadeadora de aprendizagem.

Entretanto, é somente a partir deste processo de verbalização do problema e socialização das primeiras hipóteses sobre "como criar danças distintas para qualquer deus" que as professoras puderam ser confrontadas com a insuficiência das suas explicações iniciais, bem como com a necessidade de melhor compreenderem o problema proposto na situação desencadeadora de aprendizagem.

O problema desencadeador de aprendizagem sintetiza as relações essenciais com as quais os sujeitos precisam lidar para apreenderem teoricamente o que é a dança. Entretanto, tais relações precisam ser reveladas para e pelos sujeitos a partir das ações concretas de estudo que lhes são propostas. É por essa razão que a compreensão do problema desencadeador de aprendizagem apresenta-se como um primeiro ponto de chegada da atividade de estudo dos sujeitos: transformar o problema, inicialmente apreendido em seu aspecto imediato, em um problema de fato mobilizador das ações de estudo dos sujeitos tendo em vista compreender as relações essenciais do fenômeno que se está estudando ${ }^{6}$.

Nessa direção, propusemos às professoras, de forma explícita, que assumissem o problema específico das sacerdotisas (realizar danças diferentes capazes de se comunicarem adequadamente com os deuses da "festa", "guerra" e "morte") e, assim, que fizessem materialmente as três danças para os referidos "deuses".

Em um primeiro momento, o problema de criação dessas três danças era, para as professoras, um "não problema”, na medida em que as danças pareciam já estar "prontas" no enunciado da situação desencadeadora de

\footnotetext{
${ }^{5}$ Respostas registradas no caderno de campo.

${ }^{6}$ Rubtsov (1996) conceitua esses problemas, respectivamente, como um "problema concreto e prático" e um "problema de aprendizagem".
} 
aprendizagem: danças compostas pelos movimentos de deslocar-se para frente, movimentar os braços, saltar e agachar. Mas, no momento em que as professoras começaram a se engajar materialmente no processo de criação dessas danças, confrontando-se com as condições objetivas inicialmente propostas pela situação desencadeadora, começaram a perceber que aquela sequência de movimentos corporais previamente dada era, de fato, apenas uma condição inicial e, como tal, deveria ser transformada por elas para poderem resolver o problema de "criarem danças capaz de se comunicarem com cada um dos três deuses". O que as professoras começaram a perceber é que existia um novo problema para agirem: o problema não era simplesmente "erguer os braços", mas poderem propor intencionalmente "de que modo" os braços seriam erguidos para cada um dos deuses. O problema, então, passa a ser percebido como um problema sobre como criar uma determinada forma para cada um daqueles movimentos corporais (LABAN, 1978).

É diante da compreensão deste novo problema que as relações essenciais da dança começam a aparecer para as professoras em suas ações de estudo, surgindo como conteúdos necessários em seus processos de busca de resolução do problema desencadeador de aprendizagem proposto.

Um processo similiar se deu quando as professoras foram confrontadas com a questão da delimitação das características dos "deuses" a serem tematizadas nas danças (o deus da "festa", da "guerra", da "morte"). Essa determinação primeira dos "nomes" dos deuses aparecia inicialmente, para as professoras, como uma "resposta já pronta" sobre a dança a ser criada. Mas no processo concreto de busca de resolução do problema de "criar as três danças", as professoras foram percebendo que também deveriam transformar essa condição inicial do problema para poderem resolvê-lo.

Determinar a intenção comunicativa (para um deus) não era uma tarefa imediata, resolvida simplesmente através da declaração do nome dos deuses e/ou pela listagem de sua função direta (festa - morte - guerra). A 
intenção comunicativa para cada um desses deuses aparecia ou se realizava somente no momento em que os sujeitos explicitavam o entendimento que tinham daqueles "adjetivos". Além disso, esse entendimento deveria se materializar não apenas nas palavras mas, sobretudo, na sequência de movimentos corporais previamente apresentada para a realização das danças.

Assim, analisar e atuar com as condições singulares sob as quais o problema desencadeador aparece para os sujeitos em suas ações de estudo ganha especial relevância no processo de organização do ensino que busca promover o desenvolvimento do pensamento teórico dos sujeitos.

Como diz Davidov (1988, p. 6, grifos no original, tradução nossa):

A essência do pensamento teórico consiste em que se trata de um procedimento especial no qual o homem enfoca a compreensão das coisas e dos acontecimentos por via da análise das condições de sua origem e desenvolvimento. Quando os alunos estudam as coisas e os acontecimentos do ponto de vista deste enfoque, começam a pensar teoricamente.

O teórico é, assim, expressão de um modo específico do pensamento que busca se apropriar do processo de surgimento e desenvolvimento de uma determinada atividade humana. Por essa razão, uma das tarefas centrais da atividade docente ao se propor trabalhar com o conhecimento teórico na escola está em organizar ações de ensino e de estudo que permitam aos sujeitos atuarem com o problema fundamental que levou a humanidade à produção daquele conhecimento que se quer ensinar (DAVIDOV, 1988; CHAIKLIN, 1999; ILYENKOV, 2007b; MOURA et al 2016). É nesta direção que a atividade formativa sobre a dança foi organizada.

O problema desencadeador de aprendizagem formulado para o estudo da dança com as professoras (descobrir a ação das sacerdotisas que lhes permitia criar danças distintas para qualquer deus) é materializado no 
ensino a partir das seguintes condições singulares: a) a existência de "três tipos distintos de danças (festa - guerra -morte), b) uma mesma sequência de movimentos corporais para todas as danças (deslocar-se para frente; movimentar os braços; saltar; agachar). Essas condições singulares a partir das quais o problema desencadeador aparece para o sujeito na atividade pedagógica permite explicitar os elementos centrais com os quais os sujeitos deveriam atuar. Ao atuar com tais elementos o sujeito pode, então, transformar o conteúdo de sua percepção sobre o problema e sobre as formas de resolvê-lo.

A tentativa material de resolução do problema desencadeador de aprendizagem (a criação efetiva de três danças diferentes a partir de uma mesma sequencia prévia de movimentos corporais), permitiu que o problema proposto na situação desencadeadora de aprendizagem começasse a se apresentar para as professoras como um conteúdo efetivo de suas ações. Ao criarem materialmente as três danças as professoras tiveram que atuar com a relação entre "a determinação de uma intenção comunicativa e a organização de formas com os movimentos corporais" (figura 2), ainda que, inicialmente, tal relação e tal atuação não se apresentassem de forma consciente para elas.

FIGURA 2: Primeiro momento das relações essenciais destacadas na atividade "Dança".

\begin{tabular}{|c|c|}
\hline INTENÇÃO \\
COMUNICATIVA
\end{tabular}$\longleftrightarrow \begin{gathered}\text { FORMAS COM O } \\
\text { CORPO/ MOVIMENTO }\end{gathered}$

Fonte: produção das autoras

Compreender a necessidade de atuar com a relação entre esses dois elementos que compõem a atividade de dança, reconhecendo nesta relação um meio necessário para resolver o problema de criação de qualquer dança, representou um primeiro ponto de chegada da atividade formativa aqui analisada. Esse primeiro ponto de chegada passou a ser, ao mesmo tempo, o 
ponto de partida efetivo de um processo de estudo da dança, na medida em que somente a partir da compreensão dessa relação inicial que as professoras puderam ser confrontadas com a necessidade de atuarem de modo cada vez mais consciente com os processos de criação da dança. A nova qualidade do problema percebido e enfrentado pelas professoras era: precisamos "erguer os braços", mas em qual direção, com qual velocidade, com que tipo de força, fazendo quais contornos no espaço?

Temos, neste momento, o confronto das professoras com a necessidade de pensarem os processos de composição e decomposição dos movimentos corporais no tempo, espaço, força e contorno (LABAN, 1978; NASCIMENTO, 2014). Esse terceiro elemento, que sintetiza os nexos conceituais da Dança (figura 3), realiza o entendimento vigotskiano de que "A arte começa onde começa o mínimo, e isto equivale a dizer que a arte começa onde começa a forma" (VIGOTSKI, 2001, p. 42). Começar a pensar esse "mínimo" na dança significava começar a pensar a dança como uma atividade artística e, como tal, nos processos necessários para criá-la.

FIGURA 3: modelo teórico proposto para a atividade Dança ${ }^{7}$

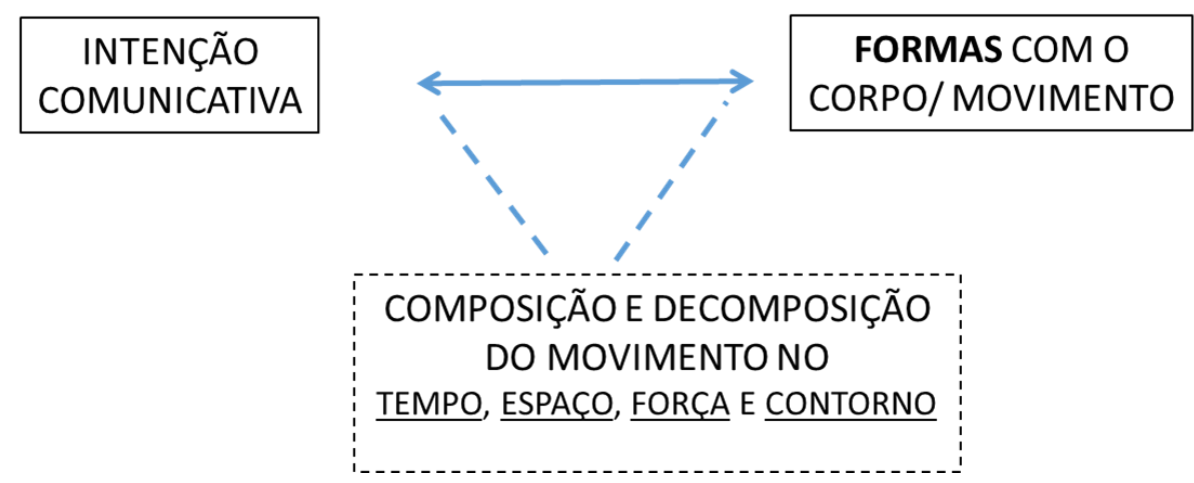

Fonte: produção das autoras

A "situação desencadeadora de aprendizagem", aqui analisada, buscava propor determinadas problemáticas que exigissem dos sujeitos

\footnotetext{
${ }^{7}$ Sobre a proposição de modelos teóricos para o campo do ensino em Educação Física ver discussões elaboradas em nossa tese de Doutorado (NASCIMENTO, 2014).
} 
atuarem com as relações essenciais que compõem a atividade humana que estava sendo estudada, no caso, a Dança. Para que os nexos conceituais da dança (figura 3), como respostas objetivamente surgidas no processo histórico de constituição da dança como atividade artística, se apresentassem como um objeto da consciência das professoras, as ações de estudo precisaram permitir, inicialmente, que as professoras atuassem materialmente com tais relações. Eis o papel central de uma situação desencadeadora de aprendizagem: mobilizar os sujeitos para que atuem materialmente com o conteúdo dessas relações a partir da proposição de um problema desencadeador e de condições iniciais para resolvê-lo que precisam ser, não obstante, transformadas pelos sujeitos-aprendizes. O conhecimento a ser ensinado aparece, então, desde o início do processo de aprendizagem, em sua dimensão de produto e processo de produção. É nesta unidade que está posta a possibilidade de trabalharmos com os conceitos teóricos no ensino e, assim, a possibilidade deste ensino efetivamente contribuir para o desenvolvimento do pensamento teórico dos sujeitos, professores e estudantes.

\section{O trabalho com o conhecimento teórico na escola: considerações didáticas e metodológicas}

A discussão sobre o significado pedagógico do trabalho com o "conhecimento teórico" na escola e sobre o que seja o "teórico" no ensino, parece ganhar especial atenção quando é realizada através de uma área que, aparentemente, trabalha com conteúdos eminentemente "práticos", caso da área de Educação Física, tratada neste artigo.

Em uma aula de Educação Física aquilo que nos é imediatamente visível refere-se ao aspecto externo das práticas corporais: os "movimentos corporais", um aspecto externo que dá materialidade à atividade dos sujeitos nessa esfera da vida. Essa forma externa da atividade dos sujeitos, imediatamente observável, é frequentemente vista e aceita como sendo a 
dimensão "prática" dos conteúdos de ensino da Educação Física, ao passo que as formas verbalizadas destas mesmas "ações práticas" (por exemplo, a "declaração de esquemas táticos" ou a "declaração do contexto histórico" de uma modalidade) seriam formas ou expressões "teóricas" dos conteúdos de ensino da Educação Física.

Esse estereótipo sobre o "teórico" e o "prático" no campo da Educação Física pode dar a impressão de que o ensino deste componente curricular esteja fadado a sempre "ensinar aos alunos a contar com os dedos" 8 . Mas do mesmo modo que o problema pedagógico, no campo do ensino da Matemática, não é que os alunos "contem com os dedos", que realizem essa ação externa de contagem, mas a qualidade do problema proposto para que se engajem com as tarefas de contar, o problema pedagógico na Educação Física não é que as crianças "dancem”, “joguem”, "lutem” etc., mas na qualidade do problema proposto para que os estudantes façam "movimentos corporais" nas aulas. Quais foram os problemas surgidos na prática social que levaram à criação dessas formas específicas da atividade humana a que chamamos Jogo, Dança, Luta, Ginástica etc.?

Reforça-se, por meio da singularidade da área de Educação Física, a necessidade de não reduzirmos a dimensão "teórica" dos conhecimentos no trabalho escolar com a adoção de ações didáticas verbalizadas ou gráficas, tal qual o trabalho com "definições" dos conceitos. Como diz Vigotski (2009, p.250, grifos nossos) "[...] no momento em que a criança toma conhecimento pela primeira vez do significado de uma nova palavra, o processo de desenvolvimento dos conceitos não termina, mas está apenas começando".

Assim, se queremos que um determinado conhecimento apareça no ensino em sua dimensão teórica não é suficiente garantir a "exposição verbal” desse conhecimento. Por mais corretas que possam estar essas

\footnotetext{
${ }^{8}$ A metáfora de "contar com os dedos" para o ensino na área de Educação Física termina, justamente, aqui. Isto, porque, há uma diferença substancial entre as ações externas no campo da matemática (contar com dedos, pedrinhas etc.) e no campo da Educação Física (o "fazer" corporal). No caso da Educação Física essas ações externas não são simplesmente um meio auxiliar que, como tal, poderia ou deveria ser "retirado" em outra etapa do processo de aprendizagem dos sujeitos, mas são o suporte material a partir do qual toda a atividade do sujeito nessa esfera da vida se realiza e deve seguir se realizando em níveis cada vez mais complexos.
} 
"definições conceituais", ao serem apresentadas, no ensino, como meras "verbalizações" do conceito, tendemos a direcionar o pensamento dos sujeitos para a tarefa de classificar o mundo a partir daquela definição, substituindo "[...] a apreensão do conhecimento vivo pela apreensão de esquemas verbais mortos e vazios (VIGOTSKI, 2009 p.247), ou, como diz Ilyenkov (2007a p.21), transformando as verdades em "verdades mortas".

Neste sentido, a defesa do trabalho com o conhecimento teórico na escola não se refere à determinação de uma forma de ensino na qual a "prática" ou as ações de professores e estudantes sejam prioritariamente ou mesmo exclusivamente "verbais". Como argumenta Vigotski, "em tais casos a criança não assimila o conceito, mas a palavra, capta mais de memória que de pensamento e sente-se impotente diante de qualquer tentativa de emprego consciente do conhecimento assimilado" (VIGOTSKI, 2009 p.247).

Sendo o conhecimento teórico expressão de um determinado movimento do pensamento que busca apreender os processos de surgimento e desenvolvimento de um certo fenômeno, um dos principais potenciais formativos, ao se defender o trabalho com o conceito teórico na escola, está na possibilidade dos sujeitos da atividade pedagógica, professores e estudantes, estabelecerem uma relação cada vez mais analítica com os conteúdos trabalhados na atividade pedagógica. Para tal, o objeto da atividade de ensino e de estudo deve expressar, simultaneamente, o produto e o processo de produção de um determinado conhecimento.

Como procuramos demonstrar na situação formativa analisada neste artigo, a intencionalidade educativa de contribuir para o desenvolvimento do pensamento teórico dos sujeitos pôde ser objetivada por meio da situação desencadeadora de aprendizagem. Nesta, buscou-se reconstituir o processo de desenvolvimento lógico-histórico do conceito "dança" através de um problema desencadeador de aprendizagem que permitiu às professoras participantes desempenhar uma atividade capaz de reconstituir as características essenciais da atividade humana encarnada no conceito (LEONTIEV, 1978). 
Considerando, novamente, o campo da Educação Física, como singularidade a partir da qual discutimos o processo de organização do ensino para a formação do pensamento teórico, poderíamos nos perguntar: quais seriam, então, os problemas específicos que deveríamos resolver ao nos engajarmos no estudo de atividades como o Jogo, a Dança, a Luta, a Giástica etc.? Por que e como o homem precisou "dançar", "lutar" ou "jogar"? Qual o sentido social de se trabalhar com esses "conteúdos" na escola? Como nos engajamos em um processo de estudo das atividades da cultura corporal (COLETIVO, 1992) na perspectiva de nos apropriarmos de uma dimensão teórica de seus conhecimentos?

A posição que temos defendido (NASCIMENTO, 2014; 2018) é a de que os significados das atividades da cultura corporal sintetizam ações criadoras que foram historicamente produzidas e materializadas nessa esfera da vida. Essa dimensão criadora das atividades da cultura corporal refere-se, fundamentalmente, a seu potencial de evidenciar para os sujeitos a capacidade humana de transformar aquilo que a atividade é naquilo que ela pode vir a ser. A "criação" faz do sujeito "um ser projetado ao futuro, um ser que cria e transforma seu presente" (VIGOTSKY, 2004, p. 6, tradução nossa).

Sendo assim, apropriar-se desses significados no campo da cultura corporal torna-se relevante no processo de constituição da subjetividade dos educandos na medida em que se configura em uma forma particular de encarnar a dimensão voluntária, consciente e criadora da conduta humana, expressões de um desenvolvimento cultural do sujeito (VYGOTSKI, 1995). Conhecer conceitualmente a Dança não significa "falar" sobre sua história ou mesmo sobre seus "nexos conceituais" (por exemplo, "declarar" que a dança seja a síntese entre "uma intenção comunicativa e a criação de formas com os movimentos corporais"). Tais "falas" podem ser, para os sujeitos que as declaram, simplesmente "verdades mortas", como disse Ilyenkov (2007a). Apropriar-se do conceito teórico da Dança implica em poder modificar-se como sujeito, em compreender qual é a atividade humana necessária para 
gerar todos esses fenômenos singulares a que chamamos Dança e compreender como essa atividade singular permitiu à humanidade um passo a mais em sua jornada de luta pelo domínio consciente da conduta.

Neste sentido, ainda que não seja possível afirmar que as professoras participantes da situação formativa analisada neste artigo tenham se apropriado do conceito teórico da Dança, podemos afirmar que o ensino proposto permitiu desencadear esse processo ao possibilitar que as professoras modificassem a qualidade do problema percebido bem como se conscientizassem da unidade deste problema com as respostas dadas a ele.

O pensamento, para Vigotski (2009), é uma ação que está sempre direcionada a resolver algum problema, "todo pensamento tem movimento, curso, desdobramento, em uma palavra, o pensamento cumpre alguma função, algum trabalho, resolve alguma tarefa" (VIGOTSKI, 2009, p. 409, grifos nosso), expressando uma determinada necessidade surgida historicamente em uma dada esfera da vida.

Os conceitos, propriamente ditos, encarnam e permitem que os sujeitos compreendam os vínculos essenciais de um fenômeno em seu processo de surgimento e desenvolvimento, expressando, por isso, um ato real e complexo de pensamento. O conceito, em sua dimensão teórica, constitui-se como tal e realiza-se para cada sujeito como tal apenas quando aparece em um sistema.

Fora do sistema, os conceitos mantêm com o objeto uma relação diferente daquela que mantêm ao ingressarem em um determinado sistema [...] Fora do sistema, nos conceitos só são possíveis vínculos que se estabelecem entre os próprios objetos, isto é, vínculos empíricos. (VIGOTSKI, 2009, p.379).

Essa compreensão é central para desenvolvermos uma interpretação didática da afirmação de que a escola deve trabalhar com o conhecimento teórico. Um conceito qualquer (por exemplo, "mamífero", "número", "dança”) 
começa a se revelar como conceito propriamente dito para os sujeitos da atividade pedagógica apenas na medida em que esses sujeitos atuem conscientemente com o problema humano, historicamente surgido, e que gerou a necessidade de elaboração de tal conceito. Assim, na atividade de aprendizagem, o conceito vai se constituindo como tal para os sujeitos na medida em que a atividade de ensino do professor organize ações que sejam capazes de expressar o sistema conceitual ao qual aquele conhecimento se refere.

Destaca-se, assim, um desdobramento pedagógico da premissa marxiana de que é somente a partir da atuação prática do sujeito com o objeto (por exemplo, com um conteúdo de ensino) que este objeto pode se tornar consciente para o sujeito (MARX; 2004; MARX; ENGELS, 2007; LEONTIEV, 1983). A criação pedagógica de ações materiais que encarnem as relações essenciais do conceito é o fundamento primário para que se possa, então, sistematizar verbalmente tais relações. Esta verbalização, adquirida como resultado da ação de estudo do sujeito para resolver um determinado problema (e não como uma pura premissa para suas ações de estudo), passa a ser o novo ponto de partida da atividade de aprendizagem deste sujeito, permitindo que ele estabeleça uma relação cada vez mais consciente e autônoma com o conceito estudado.

A questão sobre o problema proposto para os sujeitos na atividade pedagógica e as condiçoes singulares a partir das quais os sujeitos devem resolver tal problema representa um núcleo fundamental para a atividade docente de organização do ensino. Como diz Ilyenkov (2007b, p.73, tradução nossa).

Toda a arte [do trabalho] dos pedagogos deve, desde o início, concentrar-se não em inculcar regras já estabelecidas, consideradas como ferramentas ou instrumentos da ação, mas em organizar as condições externas e objetivas sob as quais a atividade de estudo deve ocorrer [...] E quando essa ação for 
realizada, o pedagogo pode e deve trazer à luz a regra ou esquema ao qual tal ação foi forçada a cumprir. Então, a esta regra, pode e deve ser dada uma expressão em palavras e sinais [...] a regra pode ser trazida à consciência verbalizada.

Retomamos, aqui, a posição vigotskiana de que o conceito não se encerra na palavra. Os nexos conceituais de um dado fenômeno devem aparecer inicialmente como produto das ações de estudo do sujeito tendo em vista solucionar um dado problema e não, simplesmente, como uma resposta a um problema que este sujeito ainda nem sequer compreendeu que exista. Esta é a principal insuficiência de um trabalho pedagógico que inicie as ações didáticas pelas definições conceituais, ainda que tais definições sejam, em si, absolutamente corretas.

Se do ponto de vista da atividade de ensino do professor o conceito, em sua forma elaborada e, ao mesmo tempo, simbolizada (como conjunto de definições) apresenta-se efetivamente como um ponto de partida para sua atividade, para o estudante-aprendiz, o conceito como tal só pode aparecer como um ponto de chegada de sua própria atividade: como resultado de seu esforço em compreender e resolver um determinado problema que deu origem a tal conceito. O conceito aparece, então, como resposta necessária à resolução daquele problema.

As ideias de Ilyenkov, citadas anteriormente, constituem o fundamento de todo o processo de organização do ensino discutido neste artigo. Ao trazermos sua fala neste momento final do texto buscamos evidenciar a seguinte questão: a necessidade de não tratarmos, em nossa atividade docente e de pesquisa, os princípios educativos presentes na teoria Histórico-Cultural e, particularmente, no ensino desenvolvimental (DAVIDOV, 1988), como "regras já estabelecidas", como respostas a problemas que, talvez, ainda nem se quer compreendemos que existam.

Uma compreensão efetivamente teórica dos princípios didáticos e pedagógicos presentes na Teoria Histórico-Cultural dá-se na medida em que 
tais princípios possam ocupar o papel de relações necessárias com as quais atuamos ao buscarmos resolver o problema sobre como organizar um ensino promotor do desenvolvimento. Ao nos engajarmos com essas ações concretas de elaboração e análise de um ensino direcionado ao desenvolvimento do pensamento teórico dos sujeitos, somos confrontados com a não trivialidade da ação de criação de "condições externas, objetivas, a partir das quais a atividade de estudo ocorre" (ILYENKOV, idem). Tal qual as professoras relatadas neste artigo, passamos a descobrir novas qualidades no problema sobre "como organizar o ensino promotor do desenvolvimento do pensamento teórico dos sujeitos". A percepção desta "nova qualidade" do problema nos permite, então, sermos cada vez mais conscientes das relações com as quais precisamos necessariamente atuar para nos engajarmos nos processos de elaboração e/ou análise de situações de ensino em uma perspectiva Histórico-Cultural da formação humana. Talvez, então, a afirmação vigotskiana de que "o único bom ensino é o que se adianta ao desenvolvimento" (VIGOTSKII, 1988) comece a ter para nós, cada vez mais, um sentido conceitual e não, apenas, de uma pura "definição".

\section{Considerações finais}

Buscamos sistematizar nesse artigo o processo a partir do qual os conhecimentos teóricos propostos para o ensino podem se tornar objeto de conhecimento dos sujeitos que atuam na atividade pedagógica, professores e estudantes. Considerando a perspectiva da Teoria Histórico-Cultural, o pressuposto que sustentou as argumentações foi a compreensão de que por mais explícito (verbalizado, declarado) que pareça estar um determinado conhecimento, este aparece para os sujeitos da atividade pedagógica sempre como uma possibilidade. Para tornar essa possibilidade uma realidade, o sujeito precisa "efetuar a atividade correspondente à que é concretizada no objeto ou fenômeno considerado" (LEONTIEV, 1978, p. 341 ).

Retomando o pressuposto marxiano e leontievano de que um "objeto" faz-se objeto do sujeito somente mediante a sua atuação prática com ele 
(transformando-o na direção de satisfazer alguma necessidade sua), as discussões sobre o sentido pedagógico do trabalho com o conhecimento teórico na escola foi realizada a partir da análise dos processos concretos de organização do ensino: o processo de criação das condições objetivas a partir das quais os sujeitos da atividade pedagógica (professores e estudantes) atuam para que os conceitos teóricos sejam revelados para eles e por eles.

A defesa do trabalho com o conhecimento teórico na escola aparecerá de forma cada vez mais concreta para nós, professores e pesquisadores que se vinculam à perspectiva Histórico-Cultural, na medida em que forem apresentadas como parte do esforço de organização e/ou análise de um ensino promotor do desenvolvimento. Este é um dos principais valores metodológicos que nos orientam a elaborar e socializar pesquisas que lidem com a proposição de situações de ensino promotoras do desenvolvimento do pensamento teórico dos sujeitos, nas diferentes áreas de conhecimento.

\section{Referências}

ARAUJO, E. S.; MORAES, S. G. . Dos Princípios da Pesquisa em Educação como Atividade. In: Manoel Oriosvaldo de Moura. (Org.). Educação Escolar e Pesquisa na teoria Histórico-Cultural. 1ed.São Paulo: Loyola, 2017, v. , p. 47-70.

CHAIKLIN, S. Developmental teaching in upper-secondary school. In HEDEGAARD, Mariane; LOMPSCHER, Joachim. Learning activity and development (pp 187-210). Aarhus University Press, 1999.

BOURCIER, P. História da dança no ocidente. São Paulo: Martins Fontes, 2001.

CAMINADA, Eliana. História da Dança: evolução cultural. Rio de Janeiro: Sprint, 1999.

COLETIVO DE AUTORES. Metodologia do ensino da Educação Física. São Paulo: Cortez. 1992.

DAVIDOV, V. V. La enseñanza escolar y el desarrollo psíquico: investigación teórica y experimental. Moscú: Editorial Progreso, 1988.

ILYENKOV, E. V. Our schools must teach how to think! Journal of Russian and East European Psychology, v. 45. N 4, 2007a. 
A contribution on the question of the concept of "activity" and its significance for pedagogy. Journal of Russian and East European Psychology, v. 45. N 4, 2007b.

KOPNIN, P. V. A dialética como lógica e teoria do conhecimento. Rio de Janeiro: Civilização Brasileira, 1978.

LABAN, R. Domínio do movimento. Rio de Janeiro: Summus, 1978.

LEONTIEV, A. N. Actividad, conciencia y personalidad. Havana: Pueblo y educacion, 1983.

.O desenvolvimento do psiquismo. Lisboa: Livros Horizonte, 1978.

MARX, K. Manuscritos econômico-filosóficos. Tradução (do alemão) Jesus Ranieri. São Paulo: Boitempo, 2004.

MARX, K; ENGELS, F. A ideologia alemã. São Paulo: Boitempo, 2007.

MOURA, M. O. A atividade de ensino como unidade formadora. Bolema. São Paulo, ano II, n.12, pp. 29-43, 1996.

O educador matemático na coletividade de formação: uma experiência com a escola pública. 2000. 131 f. Tese (Livre Docência em Metodologia do Ensino de Matemática) - Faculdade de Educação, Universidade de São Paulo, São Paulo, 2000.

MOURA, M. O et al. A atividade orientadora de ensino: unidade entre ensino e aprendizagem. In MOURA, M.O (org). A Atividade pedagógica na teoria históricocultural. Campinas: Autores Associados, 2016.

NASCIMENTO, Carolina Picchetti. A atividade pedagógica da Educação Física, a proposição dos objetos de ensino e o desenvolvimento das atividades da cultura corporal. 2014. 293 f. Tese (Doutorado em Educação) - Programa de Pós-Graduação em Educação, Faculdade de Educação, Universidade de São Paulo, São Paulo, 2014.

. Os significados das atividades da cultura corporal e os objetos de ensino da educação física. Movimento (ESEFID/UFRGS), Porto Alegre, p. 677-690, jun. 2018

RUBINSTEIN, S. Princípios da psicologia geral. Lisboa: Editorial Estampa, 1973.

RUBTSOV, V. A atividade de aprendizado e os problemas referentes à formação do pensamento teórico dos escolares. In: GARNIER, C. et al. (org.). Após Vygotsky e Piaget: perspectiva social e construtivista. Escola russa e ocidental. Tradução Eunice Gruman. Porto Alegre: Artes Médicas, 1996.

VIGOTSKI, L. S. A construção do pensamento e da linguagem. São Paulo: Martins Fontes, 2009. 
. Psicologia da Arte. São Paulo: Martins Fontes, 2001.

VIGOTSKY, L. S. Imaginación y creación en la edad infantil. Havana. Pueblo y Educación. 2004.

VYGOTSKI, L. S. Obras Escogidas, tomo III. Madri: Visor, 1995.

VIGOTSKII, L.V. Aprendizagem e desenvolvimento intelectual na idade escolar. In.: VIGOTSKII, L. V; LURIA, A.R; LENOTIEV, A.N. Linguagem, desenvolvimento e aprendizagem. São Paulo: Ed: Ícone, 1988.

Recebido em fevereiro de 2019.

Aprovado em junho de 2019. 